\title{
The Application of BIM Tools to Explore the Dynamic Characteristics of Smart Materials in a Contemporary Shanashil Building Design Element
}

\author{
Tamarah A. Alqalami ${ }^{*}$, Hisham Elkadi ${ }^{2}$, Hoda Al-Alwan ${ }^{3}$ \\ ${ }^{1}$ Department of Reconstruction and Projects, University of Baghdad, Baghdad, NA, Iraq \\ ${ }^{2}$ School of Built Environment, University of Salford, Manchester, M5 4WT, UK \\ ${ }^{3}$ Department of Architecture, University of Baghdad, Baghdad, NA, Iraq
}

Corresponding Author Email: T.A.Alqalami@edu.salford.ac.uk

https://doi.org/10.18280/ijsdp.150209

Received: 1 May 2019

Accepted: 2 August 2019

\section{Keywords:}

elegance, sustainability, shanashil, baghdad, BIM, 3D digital prototype, biomimetics

\begin{abstract}
Traditional architecture is known for its crafted facade features that respond to environmental, social and cultural requirements. Contemporary architecture produced façade features that attempted to enhance local design identity and local culture. Despite the advantages of modern technology, architectural elements have difficulties in fulfilling the idea of sustainable elegance that once traditional elements provided. This problem calls for an interdisciplinary design approach to deliver sustainable design solutions that positively adapt to the surrounding environment as well as maintain the state of elegance in design. With this in mind, the research aims to explore the role of new glass technologies to improve the performance and at the same time maintain the design value of traditional façade element "shanashil" in Baghdadi buildings. This research utilises BIM tools and uses smart materials to restore the lost value in design, which mimics the dynamic characteristics observed in nature, inspired by biomimetics strategies. Such qualities are found in the characteristics of smart dynamic glazing material particularly in the switchable, reversible properties of transparency and coloration efficiency. The material characteristics are attached to a 3D digital prototype to visualise the difference between dynamic and static properties through the use of technology tools Revit plugin and smart glazing virtual reality prototype. This research concludes that the dynamic characteristics of smart glazing materials are effective in delivering a multifunctional design quality to collectively blend in harmony with the surrounding environment.
\end{abstract}

\section{INTRODUCTION}

Architecture through its elements reflects its time, place and culture by linking to the past, the present and perhaps the future. As for the relationship of form and function, Sullivan states that shape itself comes after function [1]. Nevertheless, there is a debate on which one dictates the other.

Traditional architecture is used to be known for its sustainable passive design approach when it comes to its elements and materials. For example, traditional design elements, in particular, the elegant window/wall/balcony design element used in several countries in Middle-East such as Iraq and Egypt were once able to cater for the integrated design relationship of form and function in terms of enjoying daylight, shade, transparency, privacy, air ventilation and thermal comfort for its occupants with control through its decorated screen pattern. Alfetal [2] described the design pattern of Baghdadi buildings in the early 19th century as nearly universally built in the form of a quadrangle. These elements are closed wooden balconies extending out from the property boundaries on the road by 1 metre from the first floor and supported on brackets with a projecting, shading cornice. Although the houses are considered small the first floor has larger rooms and are well lit due to the use of shanashil. This is seen in Figure 1.
However, it is essential to realise that the window/wall/balcony design element which was valued throughout centuries for their qualities of its wooden screen pattern regarding transparency, privacy, and environmental control such as air ventilation, light and shade now appears ineffective, started to disappear and lose its value [3]. The same elements due to modern planning and technological advancement in addition to global warming issues and the rapid shift in building construction over the past 40 years are now merely used as a decorative feature for cultural association in modern Baghdadi buildings in Iraq [4], as demonstrated in Figure 2 [5].

As a result, there is many buildings' design nowadays follow the concept of daylight architecture through transparent glazed facade such as the advent of modern skyscrapers, to try to maximize the penetration of natural light. However, these changes affect design sustainability not just in the many concerns regarding the distinctive features of architectural design but also in the excessive energy use of lighting and air-conditioning in order to maintain an indoor healthy environment [6]. Accordingly, a new type of aesthetic appreciation is linked to new technological methods and are considered more important than preserving inherited social and cultural values.

On one hand, modern architects and planners tend to 
neglect the role of traditional elements including the centrality of privacy in the housing design process because they see the old traditional design patterns as a limitation to their freedom of design [7]. On the other hand, modern planning has limited the impact of privacy and opening of social spaces to the outside, giving unlimited visual access to indoor social contexts. This issue has led to the historical and cultural detachment that traditional cities suffered, losing the identity and efficiency of their architecture [8]. Nevertheless, traditional elements shanashil used to reflect a multifunctional design quality in which form and function relationships are not separated as they are closely connected to one another taking into consideration the identity of place and value. This concept can be explored through biomimetics particularly in their adaptable strategies, as described in (section 2).

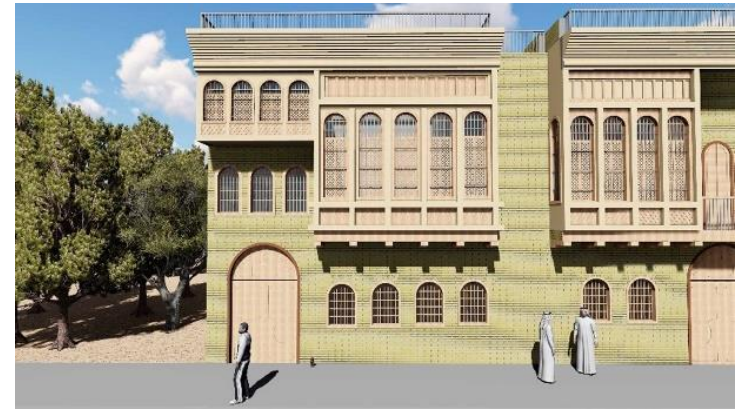

Figure 1. Different sizes of Baghdadi shanashil to prove it is flexible in a different elegant sense of form and function Source: author

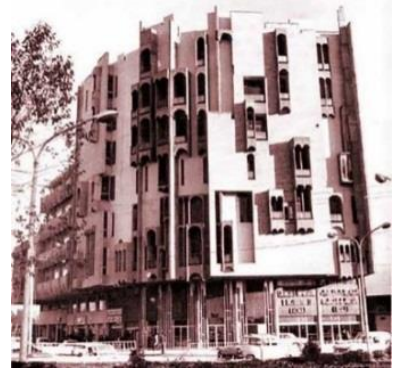

Figure 2. Union of Industries building in Baghdad design by architect Rifat Al-Chadirji in 1970 [5]

\section{BIOMIMETICS APPROACH SUSTAINABILITY IN DESIGN}

AND

This section will discuss the integrated relationships between the idea of sustainability and biomimetics strategies in design. Gruber [9] discussed that Biomimetics, in particular, uses technological tools (non-living systems) to interpret biological examples (living systems) specifically in their adaptable strategies in nature. Nevertheless, Kashani [10] noted that although the technology role in design has been inevitable in the interpretation process between natural biological examples and architecture in order to transfer ideas from nature, still the application remains a crucial goal for man-made design.

When it comes to the integrated relationship of biomimetics and sustainability, Jorna [11] argued that sustainable innovation is thought to be part of the multilayered scientific system of biomimetics in a way that collectively examines the relationship of form and function. These multiple systems can interact and provide complex patterns. A good example is seen in the eye of a moth. This eye, in particular, has a distinctive surface layer with a nanoscale pattern of conical protrusions that provide an effective anti-reflective quality where light reflection is reduced to zero, thus optimising the use of the small amount of light available at night [12], as seen in Figure 3. The complexity of the design lies beneath the layers that are part of the essence of the design process. One potential solution is that a modern facade can be made of a surface that is transparent and adopts multi-layer technologies in order to meet changing requirements.
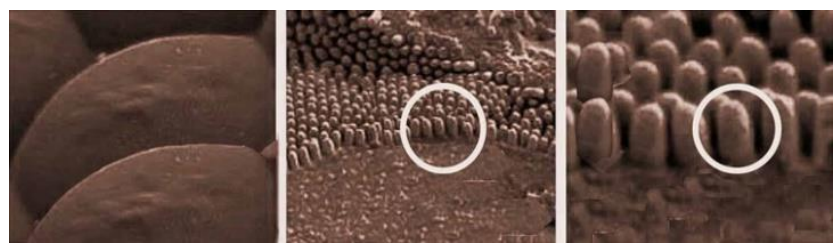

Figure 3. A detailed illustration of the moth-eye surface layer [12]

As a result, although transparency is important for the characteristics of a window`s design to be useful and efficient, the flexibility of transparent material and its properties improve the design quality of aesthetic and functional aspects.

Therefore, the next section will discuss the important role of technology in understanding the added value of modern material such as smart dynamic glazing to be applied in architectural façade. Accordingly, architecture's ability lies in understanding the relationship of form and function whether in a $2 \mathrm{D}$ or $3 \mathrm{D}$ design manipulation. However, it is important to realise that the Unity of the whole is hard to achieve.

\section{TECHNOLOGY ROLE AND SUSTAINABILITY IN DESIGN: BETWEEN STATIC AND DYNAMIC GLAZING}

The changing process in design allows technological aspects to break and combine again into an ambiguous representation that allows art to become functional in a way that enhances the aesthetic aspect [13]. Gruber [9] argued that the role of advanced technology is necessary to enable a clear understanding of overlapped patterns to be mimicked and then implemented in merged discipline and architectural projects. Further, there is an ambiguity in the meaning of the process of technology.

The contemporary design approach is focusing on developing alternative energy efficient models that are less dependent on non-renewable energy sources, such as smart material in a way that reduces the environmental impact of contemporary lifestyles. For instance, Baetens et al. [14] explained that the technology of smart dynamic glazing has been developed over the last several years to be used in many building types as an innovative sustainable approach to control heat gain and glare without blocking daylight such as Electrochromic (EC). This type of smart dynamic glazing windows can be in a double or triple type of glazing. It also changes factors such as the solar Heat Gain Coeficient (SHGC) and visible transmittance $\left(\mathrm{T}_{v i s}\right)$ properties through the flexibility in changing the glazing state between 
transparent to opaque (tinted) to adjust to outside and indoor conditions, thus reducing energy costs related to lighting, heating and cooling in addition to the ability to embrace multi-layers and various types of coatings. Accordingly, static glazing and its fixed properties is not able to provide the same flexibility that the advanced technology of smart dynamic glazing is able to provide in terms of energy savings. One of the examples, as demonstrated in Table 1 compares the energy performance of EC dynamic window glass with other conventional and high-performance static glazing in the United States. Each window type in Table 1 was modelled in a standard eight-story office building using computer simulations based on the design and maintenance of indoor environments standards of American Society of Heating, Refrigerating, Air Conditioning Engineers (ASHRAE) 90.1. 2007 national energy code.

Table 1. The performance of static glazing per ASHRAE 90.1-2007 in different U.S cities in comparison to dynamic glazing [15]

\begin{tabular}{ccccc}
\hline US Cities & Glazing State & SHGC & U-Value & $\mathbf{T}_{\boldsymbol{v i s}}$ \\
\hline Phoenix, AZ & Static-Clear & 0.25 & 0.75 & $40 \%$ \\
\hline $\begin{array}{c}\text { Washington, } \\
\text { DC }\end{array}$ & Static-Clear & 0.4 & 0.55 & $40 \%$ \\
\hline $\begin{array}{c}\text { Minneapolis, } \\
\text { MN }\end{array}$ & Static-Clear & 0.4 & 0.55 & $40 \%$ \\
\hline $\begin{array}{c}\text { Sage Glass } \\
\text { Double Pane }\end{array}$ & Dynamic-Clear & 0.47 & 0.29 & $62 \%$ \\
\cline { 2 - 5 } Synamic-Tinted & 0.09 & 0.29 & $2.0 \%$ \\
\hline $\begin{array}{c}\text { Sage Glass } \\
\text { Triple Pane }\end{array}$ & Dynamic-Clear & 0.38 & 0.14 & $52 \%$ \\
\cline { 2 - 5 } & Dynamic-Tinted & 0.05 & 0.14 & $1.9 \%$ \\
\hline
\end{tabular}

The Analysis was conducted for three different United States (US) climates; Minneapolis which represents a cold climate that is dominated by a heating load; Phoenix AZ known for hot and dry weather in which daylight is prevalent and a cooling load is dominant throughout the year; and Washington, D.C. which represents a composite climate that has both extreme heating and cooling seasons [15].

As a result, the use of EC glazing, for instance, in Phoenix AZ delivers less energy consumption opportunities in comparison to other types of glazing as shown in Figure 4.

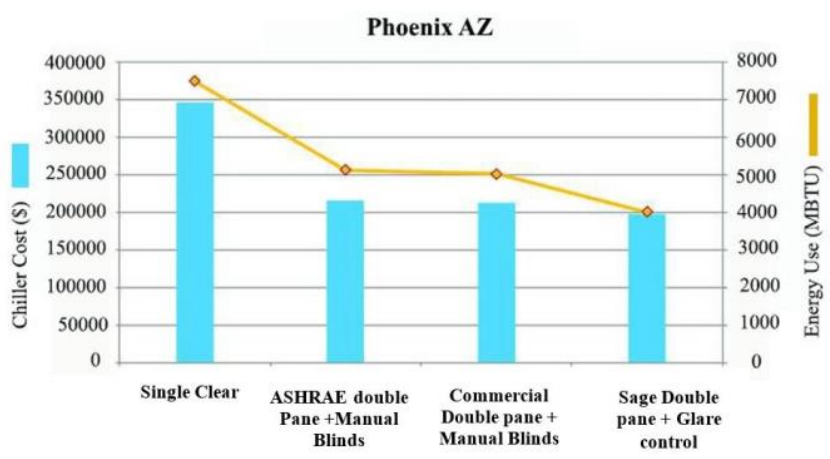

Figure 4. The advantages in the use of EC by Sage double glazing type in Phoenix, AZ among other glazing types in relation to overall energy use and cost [15]

The use of EC as a smart window-wall design element, when compared to static glazing, improves thermal and visual comfort by reducing glare, lighting energy up to $26 \%$ and cooling energy up to $20 \%$ as well as $15-24 \%$ peak demand reduction. More importantly, credit systems are important to consider when implementing new materials such as the Building Research Establishment's Environmental Assessment Method (BREEAM) in improving environmental, comfort or health benefits whilst achieving sustainable buildings [16]. In terms of the number of buildings certified, BREEAM is the biggest certification scheme in the world, with 200,000 buildings certified and over one million registered [17].

Further, Lampert [18] argued that over the last ten years about 200 US and international patents have been granted per year on EC. The major advantages of EC materials are that they require a small voltage to switch (1-5 V) and only during switching. The use of dynamic glazing offers flexibility in solar and glare control as well as in shapes and the range of colours. Thus, architects and building owners have more freedom in optimizing daylight and reducing energy consumption in buildings by allowing them to incorporate dynamic glass instead of the conventional glass in several design elements such as windows, skylights, or any curtain wall scenario [19]. In addition, the development of highly insulating dynamic windows for application in both the commercial and residential sector could save about $4.5 \%$ of the annual energy used in the United States [20]. As a result, the use of EC glazing delivers less energy consumption in comparison to other types of glazing and different types of climate zones.

With dynamic glass, designers do not have to make a compromise between SHGC and $\mathrm{T}_{\text {vis. }}$. With static glass, designers must pick one set of SHGC and $\mathrm{T}_{\text {vis }}$ properties and then live with it for the life of the building.

The next section will discuss in depth the role of technology tools to clearly demonstrate the dynamic material characteristics in a $3 \mathrm{D}$ digital prototype to enhance interactivity and engage the end users such as architects, to be part of this design process.

\section{CASE STUDY}

When discussing the state of sustainable elegance, the traditional elements were imprinted deeply in the identity of Baghdadi façade design architecture in a way that simultaneously provided transparency, light, shade and privacy through the adaptability in the screen design pattern, order and colour. Nevertheless, all of this has changed due to the loss of thermal comfort of shanashil which affected the relationship of form and function.

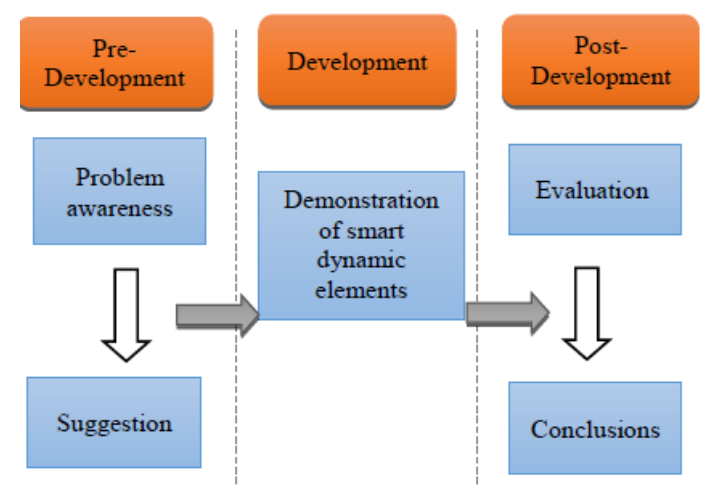

Figure 5. Methodological approach based on Figure of the General Design Cycle [21] 
Therefore, the research main aim is to revive the environmental control that the design elements used to deliver taking into consideration the need for new adaptable strategies such as the choice of smart dynamic material. This is in order to adapt to the changes in the surroundings and be able to maintain aesthetic appreciation of screen design pattern. The research subject uses the Design Science methodology in which the process stages have outputs at each step. Figure 5 illustrates the design science approach applied to this research.

The research design approach can be summarised as in the following three stages:

\subsection{Pre-development stage}

The first stage is about assessing and identifying new adaptable strategies for reviving the sustainability of environmental, social and cultural aspects to match the qualities of well-known traditional design elements shanashil, as mentioned in section 1 through the inspiration of biomimetics strategies in section 2 . Section 3 is also focused on identifying existing smart dynamic glazing material such as EC for its switchable, reversible properties associated with transparency, privacy and colour and most importantly its impact on the factors which are SHGC and Glazing state $\left(\mathrm{T}_{\text {vis }}\right)$, as illustrated in Table 1 to deliver a multifunctional design quality, aesthetically and functionally. It is important to illustrate the integrated relationships of such properties with design aspects to enhance design quality to deliver aesthetic satisfaction within the sustainability aspects.

This is achieved through understanding the state of elegance, flexibility and its integrated relationship with environmental, social and cultural sustainability. Based on the conceptual framework, the challenges of developing a smart dynamic window/wall/balcony element are strongly connected to its switchable and reversible properties such as transparency and colour. Such challenges are associated with the dynamic characteristics of a smart glazing material in terms of transparency, colour, privacy, and energy efficiency. Hence, this research will develop as a solution a 3D digital prototype that integrates the dynamic characteristics of a smart window/wall/balcony design element to help architects make conscious decisions about using switchable, reversible properties in design, both aesthetically and functionally. To meet these challenges the following Design Science Development Stage is followed to illustrate the added value of dynamic material characteristics implemented to be part of architectural elements.

\subsection{Development stage}

The research subject is majoring on 2 different issues:

- The use of advanced technology (smart material) to enable architects and designers to be able to manipulate and understand the difference between dynamic and static characteristics.

- It is not just the total presentation or about the details, it is about the concept and potentials of using the tools in this way to revival environmental comfort which traditional element used to provide, aesthetically and functionally.

Consequently, the Development Stage is where most of the actual design takes place with the creative effort required in reorganizing and visualising the dynamic material characteristics when compared to static ones in a contemporary window/wall/balcony design element. This stage allows for comparisons between the traditional and contemporary design elements using modern material. It involves the development of a 3D digital prototype of Baghdadi buildings in order to visualise the impact of dynamic characteristics of a smart window/wall/balcony element on design quality. What is equally important is the potentials to reinvent the traditional way through the use of smart material. However, methodologically the Development Stage required development using several technology tools as follows:

(1) The first tool used tackles the demonstration of a smart window/wall/balcony design element using Revit tools created in Lumion 3D application, as shown in Figure 6 to demonstrate the difference between two 3D models. Lumion 3D uses the Revit model and allows the designer to provide the realistic visual quality of the lighting in the $3 \mathrm{D}$ environment. However, it only produces video to the end users, which limits the user's ability to navigate and change the property of the smart glazing.

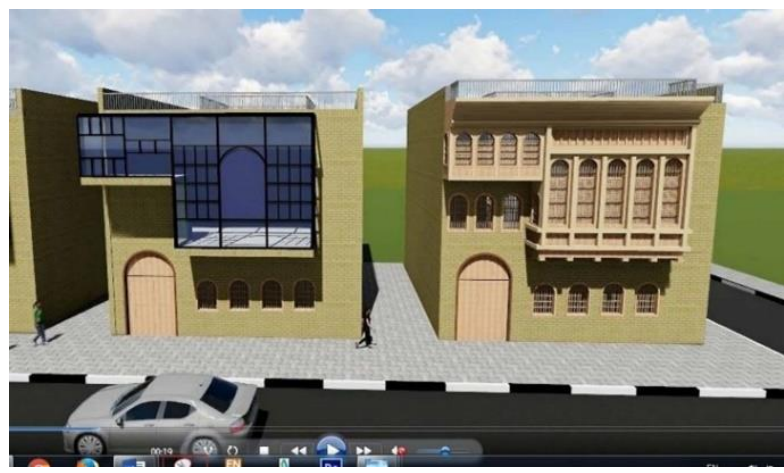

Figure 6. Smart dynamic glazing on the left, traditional one on the right, rendered in Lumion 3D Source: author

(2) Therefore, a second tool (Revit Plugin) is used to provide the opportunity to design predefined parameters such as the family of Glazing Properties associated with the smart dynamic design element, as shown in Figure 7. However, although the BIM Revit Plugin tool has the ability to deliver predefined parameters, single entities, families or instances, it is not flexible enough to demonstrate layers associated with realistic daylight condition and its integrated relationship with shadow, lighting intensity and light shaft for the flexibility of design layers to be improved.

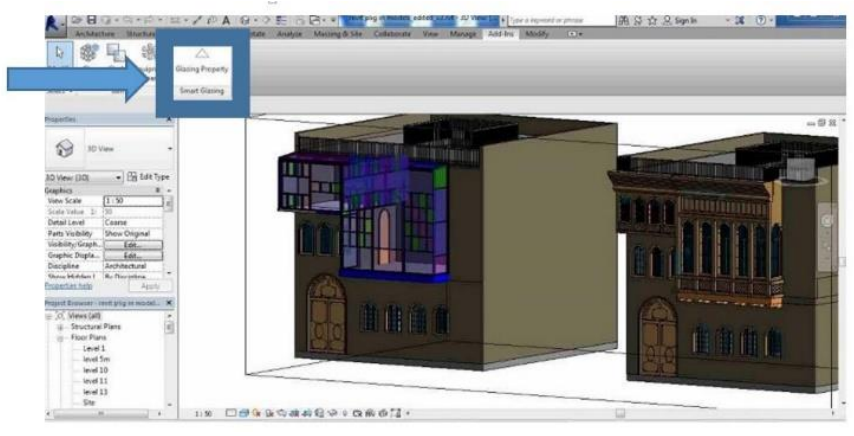

Figure 7. BIM Revit tools and Plugin for the window/wall/balcony element Source: author

(3) This leads to the third technology tool based on the 
concept of the smart serious game and it is a Smart glazing virtual reality VR prototype, as shown in Figure 6. The 3D models illustrate better interactivity by engaging the user to be part of the design process. The images captured from this prototype are illustrated to discuss the difference between the modern material and old materials in a window/wall/balcony design element regarding the role of material manipulation of transparency while maintaining private needs, order, proportion, and the choice of colour, for instance blue, as shown in Figure 8.

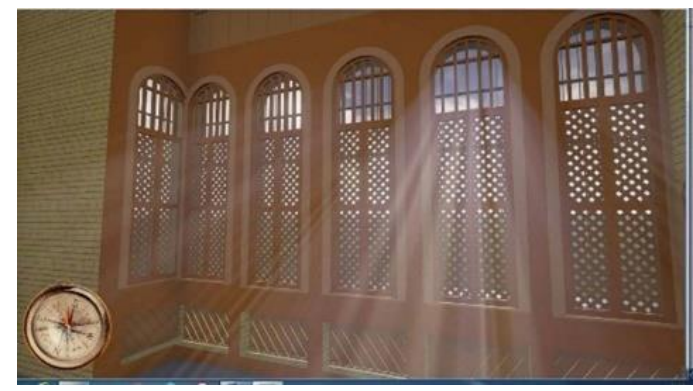

(a) Demonstration of traditional element and the integrated relationship between light, shade, and transparency Source:

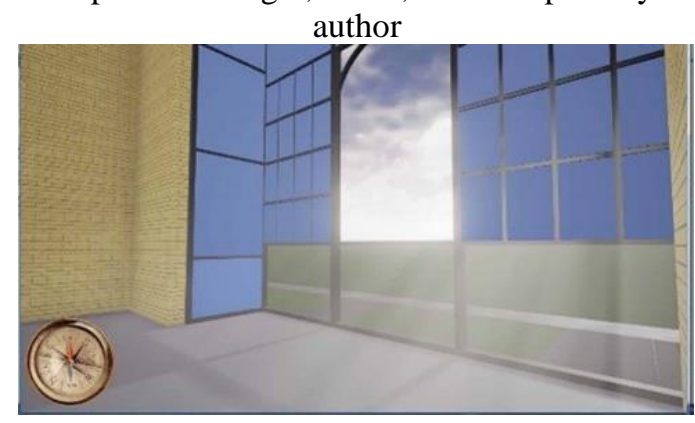

(b) Demonstration of contemprary element and the integrated relationship between light, shade, transparency and colour blue of the smart material Source: author

Figure 8. Demonstration of the difference between. (a) the traditional wooden element and (b) the contemporary smart glazing element Source: author

Nevertheless, the conclusions drawn from the design of screen pattern are summarised as:

(1) The disadvantage is that aesthetic aspects are is not reflecting the design identity and values socially and culturally in screen pattern due to the abstraction and lack of propriety in illustrating the details of the screen design pattern order, lines, arches and colour when compared to the traditional one and it.

(2) However, the advantage is that the use of dynamic glazing material in the contemporary element out-weighed the traditional static one in its functional aspects because it provides more controllable environmental aspects with better energy efficiency as well as privacy and public needs.

Thus, the appropriateness of screen design pattern order and the colour is still critical. Such an issue will be discussed further in the third stage.

\subsection{Post- development stage}

The last stage is about evaluating the efficiency of the proposed 3D digital prototype and technology tools to visualise dynamic characteristics in architectural design. To evaluate the innovative contemporary approach for the implementation of the dynamic characteristics in a smart window/wall/balcony design element in architectural façade, it is important to explore the flexibility of screen design pattern, order and colour that contributes to both the environmental, social and cultural sustainability while maintaining aesthetic appreciation to deliver an elegant, healthy, and active environment in order to develop a design solution. Accordingly, more than one 3D digital model is developed and inspired from the traditional model. The use of certain colours such as black, grey and white is more favoured in the design pattern, as seen in Figure 9.

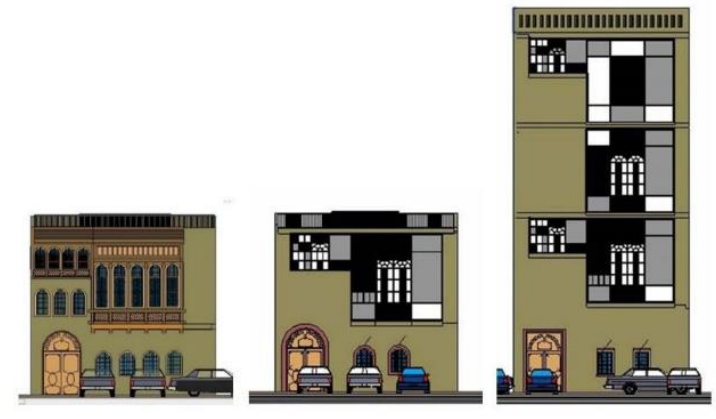

Figure 9. On the left, the illustration of the traditional wooden element in a typical example of two storey Baghdadi house. In the middle is a contemporary model with application of smart dynamic glazing elements using colours black, grey and white. On the right, the application of smart window/wall/balcony elements in a contemporary multistorey building Source: author

Table 2. The Post-Development Stage of a smart contemporary design element

\begin{tabular}{|c|c|c|c|}
\hline Post-Development Stage & Traditional element (shanashil) & Smart contemporary element & Conclusion \\
\hline $\begin{array}{l}\text { Design sustainability: } \\
\text { - State of elegance } \\
\text { relationship of form and function }\end{array}$ & $\begin{array}{c}\checkmark \\
\text { Design element combined propriety } \\
\text { of material colour, order, light, } \\
\text { shade, privacy and public needs }\end{array}$ & $\begin{array}{c}\checkmark \\
\text { To a certain extent in regards to } \\
\text { design order, and colours }\end{array}$ & $\begin{array}{l}\text {-The use of smart } \\
\text { dynamic material } \\
\text { provides: }\end{array}$ \\
\hline - Environmental & $\begin{array}{c}\mathrm{X} \\
\begin{array}{c}\text { Used to provide environmental } \\
\text { control }\end{array} \\
\end{array}$ & $\begin{array}{c}\checkmark \\
\text { Revive environmental control }\end{array}$ & $\begin{array}{l}\text {-The propriety of } \\
\text { screen design } \\
\text { pattern }\end{array}$ \\
\hline - Social and Cultural & $\begin{array}{l}\checkmark \\
\text { Harmony with surroundings, } \\
\text { location and type of climate }\end{array}$ & $\begin{array}{c}\boldsymbol{\checkmark} \\
\text { To a certain extent screen design } \\
\text { pattern and colour blends in harmony } \\
\text { with surroundings }\end{array}$ & $\begin{array}{l}\text { - The revival of } \\
\text { environmental } \\
\text { control }\end{array}$ \\
\hline
\end{tabular}


Thus, the research study acknowledges the fact that there is a need for a different material than static characteristics of conventional glazing types that can restore part of the design value in its environmental control to deliver a healthy, active environment. Accordingly, the smart material of dynamic glazing is considered as a useful adaptable strategy in design to match the changes of the surroundings, environmentally, socially and culturally. The research showed that from an aesthetic point of view there is a need for the dynamic characteristics to mimic the traditional elements to blend in harmony with the surroundings particularly in the screen pattern order, lines, arches size, and colour (see Table 2).

The research study not only identified the difference between static and dynamic material characteristics but also identified the integrated design relationship between aesthetic and functional aspects of the screen design pattern.

\section{CONCLUSIONS}

An innovative design approach has been adopted in both the Development and Post- Development Stage to clearly illustrate the added value of dynamic material characteristics of a smart contemporary window/wall/balcony element using visualisation tools in the external façade which are as follows:

- The design elements can be applied to a two-storey building or multi-storey one and can be used in different types such as residential and office buildings.

- The propriety of design order is achieved by mimicking the traditional screen design pattern in terms of lines symmetry, arches repetition, and the colours.

- A combination of three technological tools has potentials to provide better communication and to ease the visualisation of a smart contemporary window/wall/balcony element and help to identify the added value to the quality of the design, both aesthetically and functionally.

\section{ACKNOWLEDGMENT}

This research paper is based on $\mathrm{PhD}$ Thesis entitled [The Application of Visualisation Tools to Enable Architects to Explore the Dynamic Characteristics of Smart Materials in a Contemporary Shanashil Building Design Element for Hot Arid Climates] by Dr. Tamarah Alqalami.

\section{REFERENCES}

[1] Gómez, R.D. (1967). El Concreto en la Arquitectura. IMCYC Magazine (Supps 24-29). http://www.imcyc.com/historia, accessed on May 13, 2016.

[2] Alfetal, S. (2001). Traditional elements in the consistency of Iraqi identity from 1960s to 1990s. Master`s Degree, University of Technology, Baghdad, Iraq. https://www.uotechnology.edu.iq/elibrary.htm, accessed on Feb. 13, 2020.

[3] Lewis, B. (2007). A Middle East Mosaic: Fragments of Life, Letters and History. New York: Modern Library. https://books.google.iq/books/about/A_Middle_East_M osaic.html, accessed on Feb. 12, 2020.

[4] Al-Haidary, A. (2008). The Baghdad House. Baghdad: Al-Mada. https://rddlib.rdd.edu.iq/, accessed on Feb. 13, 2020.

[5] Sherzad, S. (2002). Glimps of Architectural History, Movements, and Pioneers. Amman, Jordan: Al-Faris. http://library.philadelphia.edu.jo, accessed on Feb. 13, 2020.

[6] Askar, H., Probert, S.D., Batty, W.J. (2001). Windows for buildings in hot arid countries. Applied Energy, 70(1): 77-101. https://doi.org/10.1016/s03062619(01)00009-5

[7] Eben Saleh, M.A. (1997). Privacy and communal socialization: The role of space in the security of traditional and contemporary neighborhoods in Saudi Arabia. Habitat International, 21(2): 167-184. https://doi.org/10.1016/s0197-3975(96)00055-0

[8] Abdelsalam, T., Rihan, G.M. (2013). The impact of sustainability trends on housing design identity of Arab cities. HBRC Journal, 9(2): 159-172. https://doi.org/10.1016/j.hbrcj.2013.03.002

[9] Gruber, P. (2011). Biomimetics in architecture: architecture of life and buildings. Biomimetics -Materials, Structures and Processes, pp. 127-148. https://doi.org/10.1007/978-3-642-11934-7_7

[10] Kashani, A.Y. (2012). Biomimetics and architecture an Exploration of Swarm intelligence, emergent behaviour and self-organization. Saarbrücken: LAP Lambert. https://www.amazon.com/Biomimetics-Architecture-

Exploration-Intelligence-Self-

Organization/dp/3659275824, accessed on Feb. 13, 2020.

[11] Jorna, R.J. (2006). Sustainable innovation: the organisational, human and knowledge dimension. Shipley: Greenleaf Publishing. https://trove.nla.gov.au/version/46621994, accessed on Feb. 13, 2020, accessed on Feb. 13, 2020.

[12] Cannavale, A., Fiorito, F., Tortorici, G., Manca, M., Cingolani, R., Gigli, G. (2010). Multifunctional bioinspired sol- gel coatings for architectural glasses. Building and Environment, 45(5): 1233-1243. https://doi.org/10.1016/j.buildenv.2009.11.010

[13] Al-Khafaji, S., Alkilidar, M. (2015). Civilizations and environmental particulars of place in Islamic Holy Thresholds in Iraq (Alkadhumain Holy Threshold as a case study). Journal of Engineering-University of Baghdad, 21(12): 1-27. https://doi.org/10.13140/RG.2.2.19395.91685

[14] Baetens, R., Jelle, B.P., Gustavsen, A. (2010). Properties, requirements and possibilities of smart windows for dynamic daylight and solar energy control in buildings: A state-of-the-art review. Solar Energy Materials and Solar Cells, 94(2): 87-105. https://doi.org/10.1016/j.solmat.2009.08.021

[15] Sbar, N.L., Podbelski, L., Yang, H. M., Pease, B. (2012). Electrochromic dynamic windows for office buildings. International Journal of Sustainable Built Environment, 1(1): 125-139. https://doi.org/10.1016/j.ijsbe.2012.09.001

[16] BREEAM. (2016). What is BREEAM? http://www.breeam.com/, accessed on Feb. 13, 2020.

[17] Guardian Industries. (2016). BREEAM. http://www.guardianglass.co.uk/architectural/breeam, accessed on Feb. 13, 2020. 
[18] Lampert, C.M. (1998). Smart switchable glazing for solar energy and daylight control. Solar Energy Materials and Solar Cells, 52(3): 207-221. https://doi.org/10.1016/s0927-0248(97)00279-1

[19] WBDG. (2016).

SageGlass. https://www.wbdg.org/references/cs_sageglass.php, accessed on Feb. 13, 2020.

[20] Gillaspie, D.T., Tenent, R.C., Dillon, A.C. (2010) Metal-oxide films for electrochromic applications: Present technology and future directions. Journal of Materials Chemistry, 20(43): 9585-9592. https://doi.org/10.1039/C0JM00604A

[21] Takeda, H., Veerkamp, P., Yoshikawa, H. (1990).
Modeling design process. AI Magazine, 11(4): 37. https://doi.org/10.1609/aimag.v11i4.855

\section{NOMENCLATURE}

ASHRAE

BREEAM

EC

SHGC

$\mathrm{T}_{\text {vis }}$
American society of heating, refrigerating, air conditioning engineers standards

building research establishment's environmental assessment method electrochromic solar heat gain coefficient visible transmittance 